\title{
VOLTAGE QUALITY ENHANCEMENT IN DISTRIBUTION SYSTEM USING ARTIFICIAL NEURAL NETWORK (ANN) BASED DYNAMIC VOLTAGE RESTORER
}

\author{
S. B. Ibrahim* \\ DEPARTMENT OF ELECTRICAL ENGINEERING, BAYERo UniVERSITY KANO, KANO STATE, NIGERIA \\ E-mail address: sabkibr@yahoo.com
}

\begin{abstract}
Voltage quality issue and invariably power quality has become an important issue in distribution power system operation due to presence of increased use of nonlinear loads (computers, microcontrollers and power electronics systems). Voltage sags and swells as well as harmonics are problems for industrial, commercial and residential customers with sensitive loads, which need urgent attention for their compensation. In this paper, the modeling and simulations of a dynamic voltage restorer (DVR) was achieved using MATLAB/Simulink. The aim was to employ artificial intelligence to provide smart triggering pulses for the DVR to mitigate and to provide compensation against voltage sags and swells. The Artificial Neural Network (ANN) was trained online by data generated via a 3-phase programmable voltage generator and these were used as inputs to the ANN, fault conditions were simulated to create voltage sags and swells in the source supply, while faultless condition of the system was simulated and the data obtained from it was used as targets of the ANN. A net fitting, feed forward back propagation, Lavenberg-Marquardt training algorithm and mean square error performance were used. ANN Simulink block was used as control for the gate of the full wave 3-phase Insulated Gate Bipolar Transistor (IGBT) inverter employed in constructing the DVR. Three single phase injection transformers were employed to regulate the output amplitude voltage from the DVR, while filters were used to reduce the harmonics from $11.09 \%$ to $3.5 \%$. At the end, voltage sags and swells were effectively mitigated and harmonics in the system reduced to 3.5\%, which is within the maximum acceptable IEEE standard 519 of 1992 for harmonic distortion.
\end{abstract}

Key words: Voltage, Distribution System, ANN, Dynamic Voltage Restorer, Voltage quality enhancement, non-linear loads

\section{INTRODUCTION}

Electric utilities and consumers of electrical power are becoming increasingly concerned about the quality of electric power because sensitive loads such as computers, programmable logic controllers (PLC), medical equipment (e.g. magnetic resonance imaging systems and X-ray machines), adjustable speed drives (ASD) etc. need high quality supplies to function efficiently and reliably $[1,2]$. Power quality problem can be defined as any power problem that will manifest in voltage, current, or frequency deviations that result in failure or mal-operation of electric equipment.

Electric utilities should ideally provide their customers with an uninterrupted power supply with a smooth sinusoidal voltage at the accepted magnitude level and frequency. However, in practice, power systems, especially distribution systems, have numerous nonlinear loads, which significantly affect the quality of the power supply. As a result of these nonlinear loads, the purity of the supply waveform is lost in many places. This ends up producing many power quality problems $[3,4]$.

Power quality problems may be classified according to how the voltage waveform is being distorted as: transients, short duration variations (sags, swells and interruption), long duration variations (sustained interruptions, under voltage, over voltages), voltage unbalance, waveform distortion (dc offset, harmonics, inter-harmonics, notching, noise, voltage fluctuations and power frequency variations [5]. An important percentage of all power quality problems are of the voltage-quality type where the voltage waveform deviates from its ideal form. The best known disturbances of the voltage waveform are voltage sags and swells, harmonics, inter-harmonics and voltage imbalances. 
A voltage sag is any momentary drop in the root mean square (rms) voltage to a value of between $10 \%$ and $90 \%$ of the nominal $\mathrm{rms}$ value and lasting for 0.5 cycles (10msec for $50 \mathrm{~Hz}$ power system) up to 1 minute. It is considered as the most serious problem of power quality. It is caused by faults in the power system or by the starting of large induction motor [6]. Voltage swell is defined as an increase in the rms voltage from $110 \%$ to $180 \%$ of the nominal rms voltage for duration from $10 \mathrm{msec}(0.5$ cycles $)$ to 1 minute. Voltage swells are not as important as voltage sags because they are less common in distribution systems. The main causes for voltage swell are switching of large capacitors or starting/stopping of heavy loads [4, 7]. Harmonics are distortions that are associated with both voltage and current waveforms in sinusoidal form. Though voltage harmonics are present, most of the harmonics are caused by current distortion. The main causes of harmonic distortion are rectifiers and all non-linear loads, such as power electronics equipment including Adjustable Speed Drives (ASDs) [8].

There are many different methods to mitigate voltage sags and swells, though the use of a custom power device is considered to be the most efficient method. The term custom power refers to the use of power electronics controllers in a distribution system, to specifically deal with various power-quality problems. There are many types of Custom Power devices that could be used to mitigate voltage quality issues, these include: Active Power Filters (APF), Battery Energy Storage Systems (BESS), Distribution Static Synchronous Compensators (DSTATCOM), Distribution Series Capacitors (DSC), Dynamic Voltage Restorer (DVR), Surge Arresters (SA), Super-conducting Magnetic Energy Systems (SMES), Static Electronic Tap Changers (SETC), Solid-State Transfer Switches (SSTS), Solid State Fault Current Limiter (SSFCL), Static Var Compensator (SVC), Thyristor-Switched Capacitors (TSC), and Uninterruptible Power Supplies (UPS) [9, 10]. Among the mitigation methods stated above, the dynamic voltage restorer (DVR) is considered the most effective because of its small size and low capital/maintenance cost

Several studies have been conducted on improvement of power quality of the power system using DVR. Mitigation of voltage sags using DVR under feedback and feed forward control scheme was proposed [11]. The proposed linear controller for the DVR proved to be effective and robust to the variations in load as well as in input. However, the research failed to address the issue of nonlinearity of the DVR which linear controllers cannot efficiently and effectively manage.
Modeling and simulation of DVR using Simulink in MATLAB was proposed by [12]. An abc to dq0 based control technique was used, and the simulation result showed that the DVR mitigates voltage sags and swells very fast. However, the study did not address the issue of phase balancing. DVR for voltage sags mitigation using PI with Fuzzy logic controller was proposed by [13]. The results showed that good voltage regulation was obtained by the DVR for different fault conditions. However, the work did not consider the harmonics produced by nonlinear load in the system.

A Phase Advance Compensation (PAC) strategy for DVR was proposed where a closed-loop controller that consists of an inner current loop and an outer voltage loop was incorporated into the DVR system. The analysis showed the capacitor current feedback scheme in terms of steady state error and disturbance rejection. However, the work failed to consider the effect on the DC link after the capacitor in it is discharged [14]. A control system based on dq0 technique was developed which scaled the voltage error between source side of the DVR and its reference for sags/swells correction, the simulation showed that the DVR performance is satisfactory in mitigating voltage sags/swells quickly and provides excellent voltage regulation [15].

Inverter is an important component of DVR and the performance of DVR depends on the control strategy of the inverter. The inverter control strategy can either be based on linear or non-linear control. DVR is categorized as a non-linear device because of its usage of power semiconductor switches. Thus, it can best be controlled using a non-linear control technique.

This paper presents the modeling and simulation of an ANN-based DVR under voltage sags and swells phenomena. In this case, the ANN is trained off-line, and the trained network is employed for on-line control. The input-output data pairs for training the ANN are generated using the conventional PI controller. The simulation tool used is the MATLAB/ Simulink/ Simpower tools. The capability of DVR to mitigate the voltage sags and swells is demonstrated by MATLAB simulation.

\section{MATERIALS AND METHODS}

The materials used in the work include a computer with specifications: $2.00 \mathrm{GHz}$ Intel(R) Core(TM) 2Duo central processing unit (CPU), 4GB installed memory (RAM) and 32-bit windows operating system (OS). Simulations were performed under the platform of MATLAB R2013a, using Simulink/ Simpower tools. 


\subsection{Methodology}

The steps taken in the studies include development of the Simulink model of the DVR, control of the DVR using ANN controller developed using Lavenberg Marquardt training algorithm. Training dataset was generated using the 3 phase programmable generator in the model to simulate fault conditions which served as input for the ANN.

\subsubsection{Basic Concept of DVR}

A DVR is a solid state power electronics switching device consisting of either MOSFET or IGBT, a capacitor bank as an energy storage device and injection transformer. The primary side of the injection transformer (transformer on the left side of the PCC) is rated $11 \mathrm{kV}$ and the DVR is placed in series between the low voltage four-wire $415 \mathrm{~V}$ distribution system and the sensitive load as shown in Fig. 1.

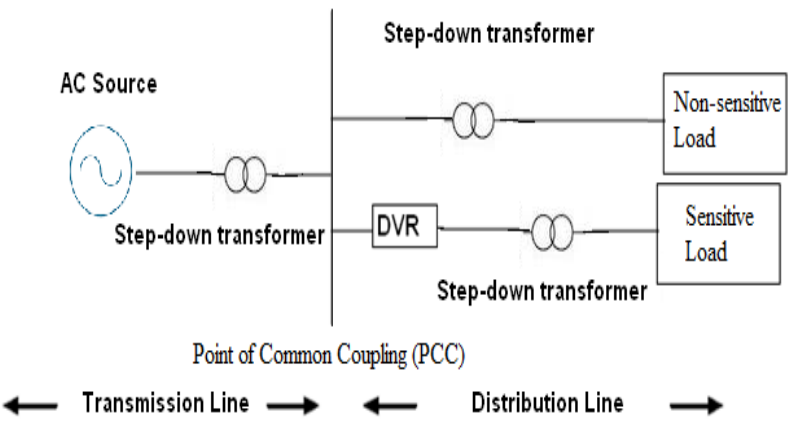

Fig. 1: Location of a Dynamic Voltage Restore (DVR)

Fig. 2 shows a typical DVR series connected topology. The DVR essentially consists of a voltage source inverter (VSI), inverter output filter and an energy storage device connected to the DC link. The basic operational principle of the DVR is to inject a controlled voltage generated by the forced commuted inverter in series with the bus voltage by means of an injecting transformer whenever voltage sags or voltage swells are detected. In addition to voltage sags and swells compensation, DVR can also perform other tasks such as harmonic compensation and Power Factor correction.

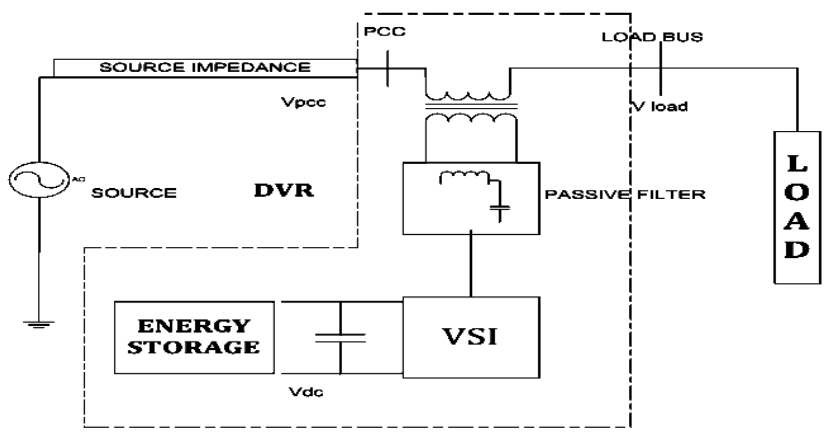

Fig. 2: DVR Series Connected Topology
The Voltage Source Inverter (VSI) converts the input DC supply from the energy storage system to the 3phase controllable AC supply. The Insulated Gate Bipolar Transistor (IGBT) based VSI gives an output with higher frequency harmonic content waveform and to mitigate this problem and provide good power quality supply a passive (LC) filter is used. The LC filter is sited next to the VSI, to reduce the switching harmonics. So the harmonic free supply is passed through the series injection transformer. Three individual single-phase transformers are used for the three phases. The operating voltage of the proposed system is $415 \mathrm{~V}, 50 \mathrm{~Hz}$. Initially the $11 \mathrm{kV}$ source voltage is stepped down to $415 \mathrm{~V}$ by step down transformer. The parameters used in the simulation of the proposed DVR are given in the Appendix. Voltage sag is initiated by phase to phase fault on the source side of the system, whereas voltage swell is simulated by phase to ground fault. Whenever voltage sag or swell is detected by the DVR, it will inject a compensating voltage through the injection transformer. Hence the voltage at the load side of the system is always sinusoidal and balanced.

The inverter is controlled in open loop with the Pulse Width Modulation (PWM) Generator block. Each phase of the inverter is made up of four IGBTs, and hence for 3 phases, 12 IGBTs are required and consequently 12 pulse triggers as depicted in Fig. 3.

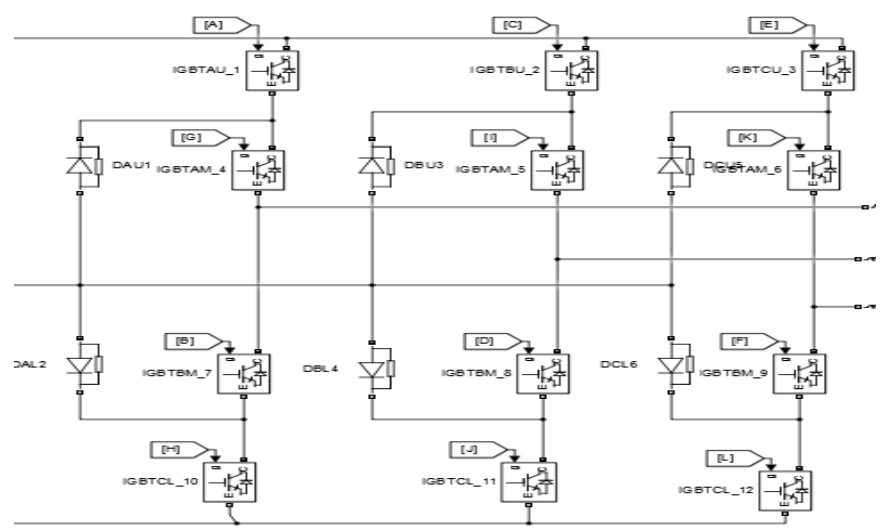

Fig. 3: Inverter Simulink Model

Two loads are connected in the distribution system: Linear load (parallel resistive, inductive and capacitive load) and a non-linear and unbalanced load (Three phase diode bridge rectifier connected to non linear resistive and capacitive load) as shown in Fig. 4.

The non-linear rectifier load is connected to the point of common coupling (PCC) through a transformer. The presence of non linear and unbalanced loads at PCC makes the voltage at PCC to become distorted. 
Similarly, a phase to phase or phase to ground fault at the source side causes voltage sag or swell at PCC.

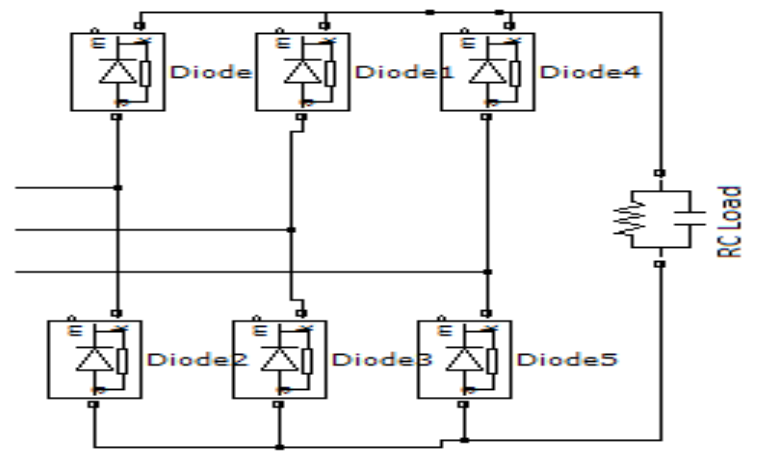

Fig. 4: Non-Linear and Unbalanced Load

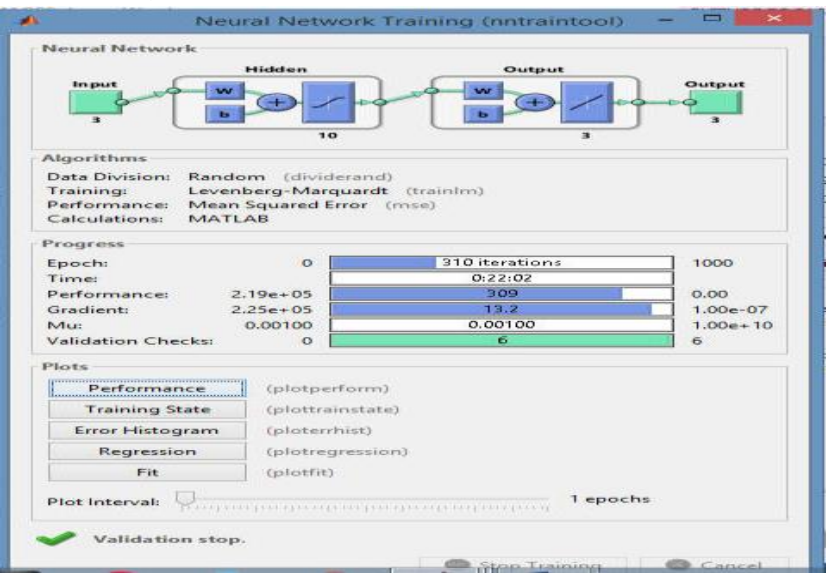

Fig. 5: Training of the ANN model

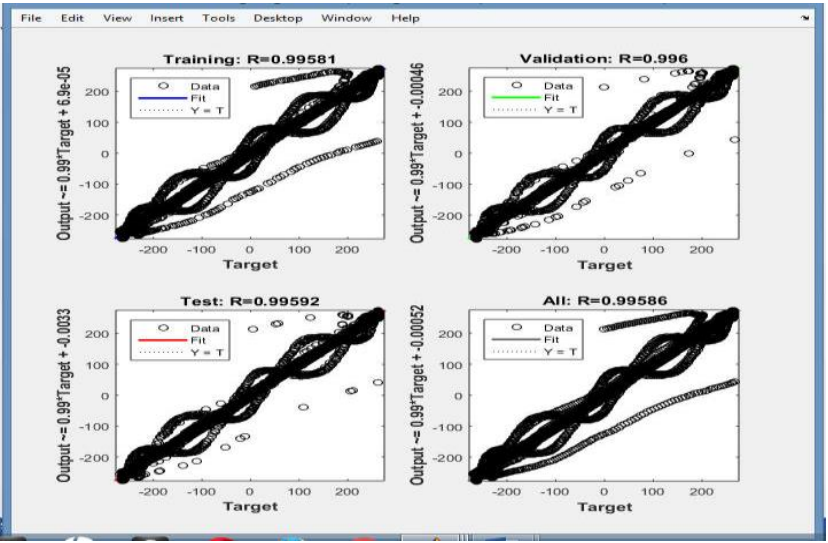

Fig. 6: Training Indicator of the ANN

\subsubsection{DVR control strategy}

Control strategy is the main part of DVR system. The main function of a DVR control system is to detect the disturbances occurring in the power system and compute the missing voltage to generate gate pulses using Discrete PWM generator, then the IGBT inverter converts the input DC voltage to a sinusoidal AC voltage through an LC filter and injection Transformer. In this paper, Fourier Transform technique is used to provide both the voltage amplitude and phase shift information while, pre-sag compensation method is considered for compensating voltage disturbances and to restore the load voltage with exact amplitude and phase. The presag compensation strategy leads to low distortion at the load side. The role of DVR control based on ANN controller is to detect the disturbance in voltage, inject the voltage difference and turn off the DVR system, when the disturbances are removed.

\subsubsection{ANN Training}

Fault conditions were generated by variation of the voltage per unit values to create voltage sags and swells via a $3 \phi$ programmable voltage harmonics generator, and these ware used as inputs to the ANN The Artificial Neural Network (ANN) was trained offline by data generated via a 3-phase programmable voltage generator, fault conditions were simulated to create voltage sags and swells in the source supply and these were used as inputs to the ANN, while faultless condition of the system was simulated and the data obtained from it was used as targets of the ANN. There are many different ANN training algorithms, with different characteristics and performance, namely: Gradient descent, Newton's method, Conjugate gradient, Quasi-Newton method and Levenberg-Marquardt (LM) algorithm. However, of all the training algorithms the LM training algorithm was found to be significantly the most efficient. It was evident that the LM algorithm was the fastestconverging algorithm and performed with high accuracy compared to the other training algorithms. Thus the time spent on ANN training depends on the algorithm used.

A net fitting, feed forward back propagation, Lavenberg-Marquardt training algorithm and mean square error performance were used in the training. The training time was 22 minutes for 310 iterations executed. The training window is shown Fig. 5.

The best results of the training occurred from Epochs 75 upwards to 310 . The regression plot which shows the relationship between the outputs of the network and the targets attained a regression of 0.99 as shown in Fig. 6.

The outputs of the ANN controllers provide the modulating signals to generate the IGBT pulses. These output signals are obtained by dq0-to-abc transformation. To improve the performance of the DVR, a multi-layer feed forward network is designed with three layers namely 1 input layer, 10 hidden layers and 1 output layer for the controller. The hidden layer neurons have tangent sigmoid function as the activation function and the output neurons have linear activation function. The input and output data of the 
conventional PI based DVR are collected and stored in MATLAB workspace. These data are used for training the ANN. The neural network training is performed offline utilizing a previously generated training data set. The mean squared error is selected as a performance quantifying parameter for the back-propagation training of the neural network model. Fig.7 shows simulation diagram of the DVR using ANN controller, a three phase rectifier with parallel resistive /capacitive dc load was connected as nonlinear load to create a disturbance in the source side and to demonstrate the performance of the DVR under non-linear condition.

\section{RESULTS AND DISCUSSIONS}

The work is validated by the simulation results of MATLAB/Simulink. DVR with ANN control is applied to protect a sensitive load under voltage disturbance conditions. In this work, two different cases are considered for the validation as depicted by Figs. 8 and 9. The simulation is realized with the integration of the supply source with phase to phase fault to create the sag ( $50 \%$ of nominal voltage value) and phase to ground fault to introduce swell (25\% above nominal voltage). Voltage swell and sag are generated between $0.2 \mathrm{~s}$ to $0.4 \mathrm{~s}$ and $0.5 \mathrm{~s}$ to $0.7 \mathrm{~s}$ respectively.

\subsection{Case 1: Simulation Without DVR Connected to the distribution system}

Fig. 8 shows the sag and swell generated on the source side while Fig. 9 depicts the voltage developed across the sensitive load without the incorporation of DVR.

It is clear from Fig. 9 that the disturbance noticed on the source side (Fig. 8) of the system is transferred to the load, and this can cause failure or mal-operation of the load especially if it is of the sensitive type. Based on Fast Fourier Transform (FFT) analysis the total voltage harmonics distortion (THDv) produced by the nonlinear load when ANN based DVR was not connected is $11.09 \%$ as shown in Fig. 10.

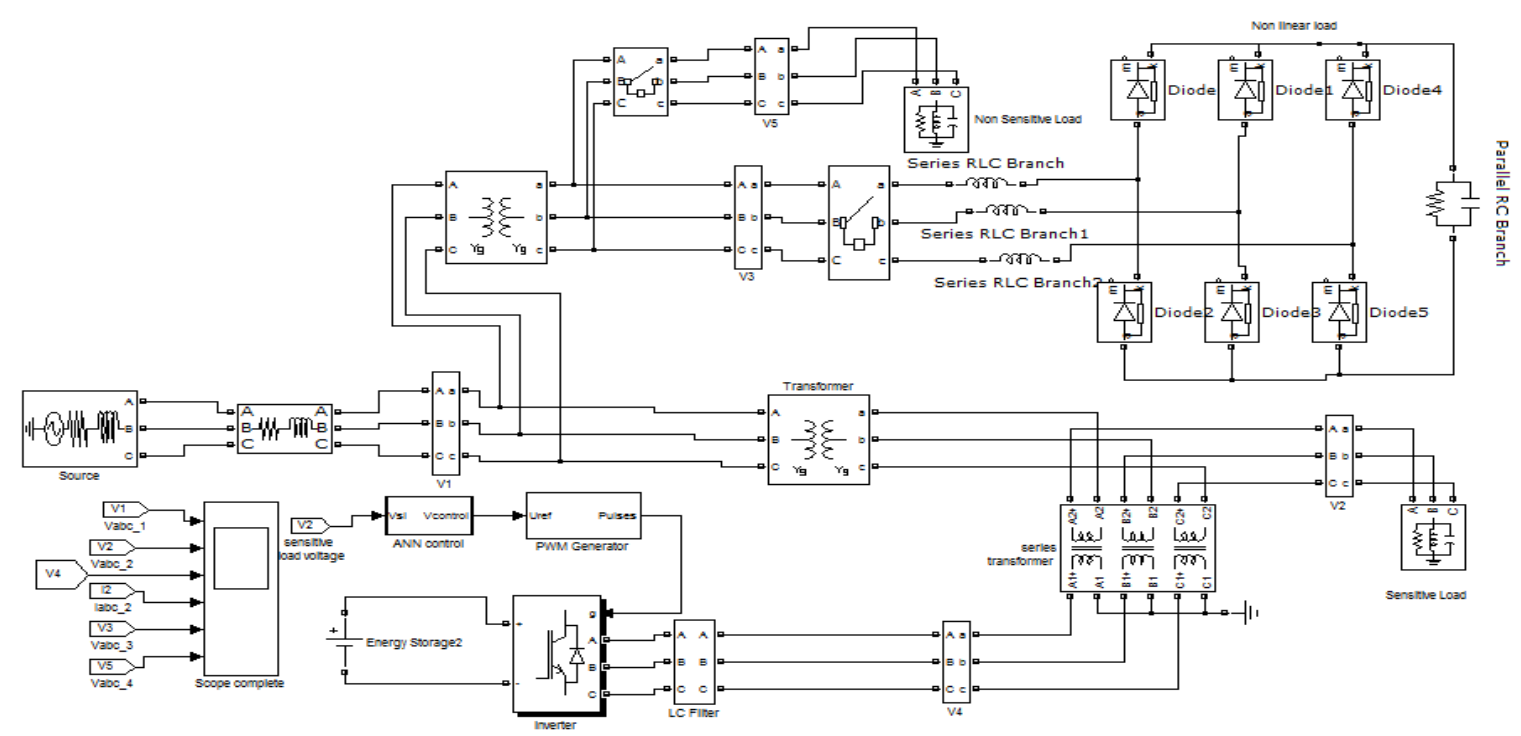

Fig. 7: Simulink Model of DVR using ANN Controller under Non-linear Load Condition

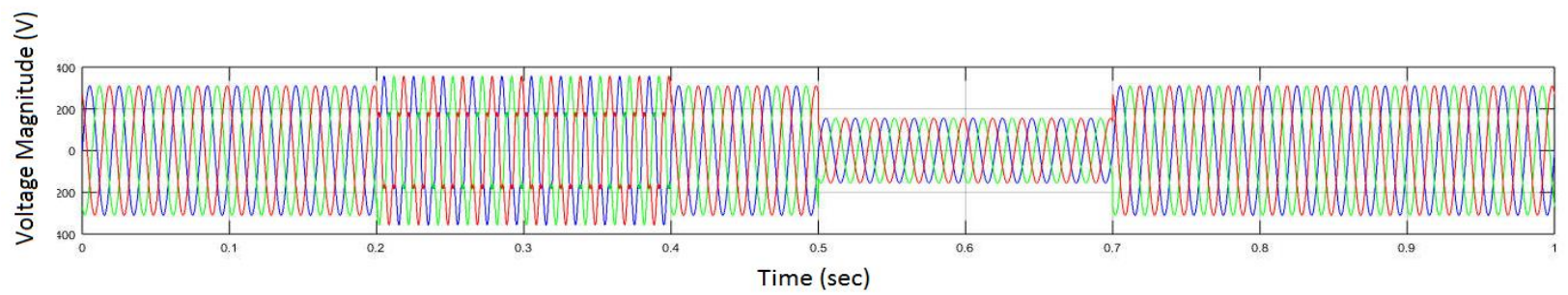

Fig. 8: Voltage Waveform showing Generated Sag and Swell at the Source Side

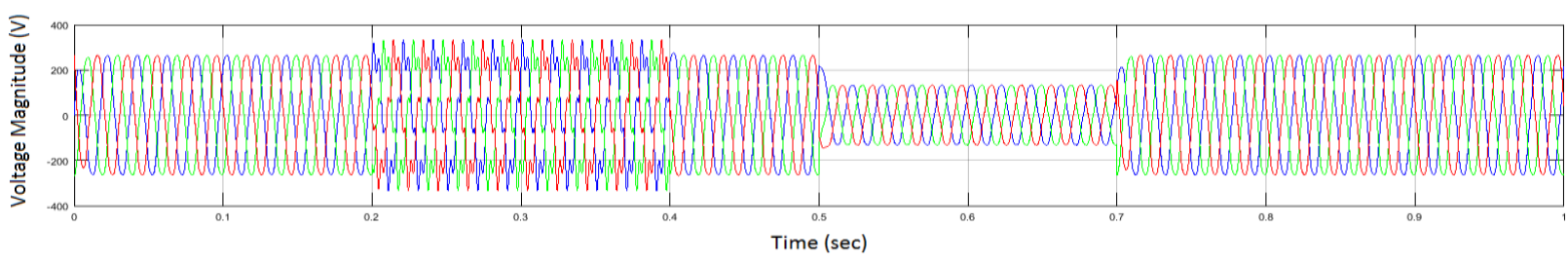

Fig.9: Voltage Waveform across the Load without DVR Incorporation 


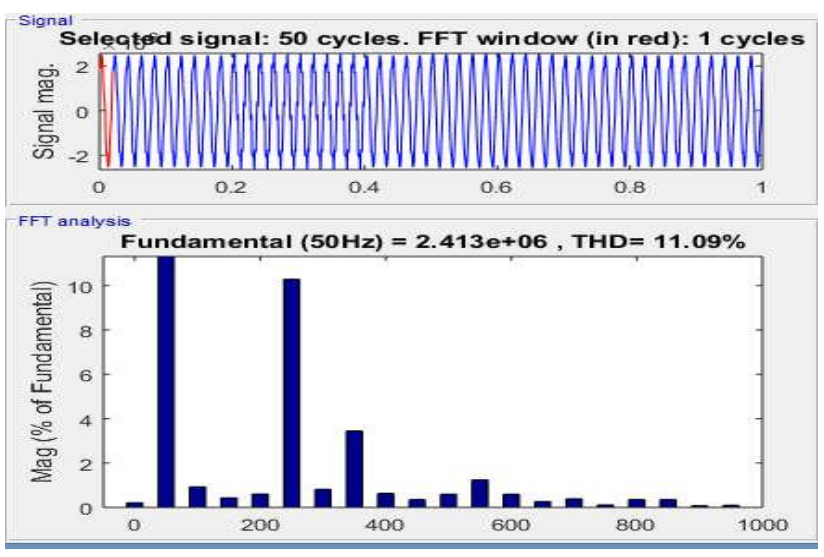

Fig. 10: THDV Developed on the Sensitive Load without DVR

The value of the THDv is above the 5\% (maximum limit) harmonics allowable by IEEE standard 519 of 1992, hence it is undesirable for stable power operation, especially for sensitive loads.

\subsection{Case 2: Simulation with Sensitive Load connected through ANN-Based DVR}

Fig. 11 shows the sag and swell generated on the source side, while Fig. 12 depicts the voltage developed across the sensitive load with the incorporation of DVR. Fig. 12 shows that when the load is connected through a DVR, the load voltage stabilized to its nominal value both in magnitude and phase by the action of the DVR. The result indicates the ability of the DVR to absorb the reactive power during swell and inject active power to mitigate the sag.

When ANN is used to control the DVR, the THDv associated with the load connected through the DVR is observed to have dropped to $3.5 \%$, which is within the allowable range as shown in Fig. 13.

\section{CONCLUSION}

In this paper, the modeling and simulation of DVR controlled by Artificial Neural Network (ANN) controller has been achieved using MATLAB/Simulink. From the results obtained, the ANN based DVR effectively mitigates voltage sags, swells associated with the grid side and also reduced the load harmonics from $11.09 \%$ to $3.5 \%$, which is within the acceptable THDv limit recommended by IEEE standard for THDv. The proposed DVR handles different fault condition like, single line to ground fault and line to line fault without any difficulties and injects the appropriate voltage component to correct any fault situation that occurred in the supply voltage to keep the load voltage balanced and constant at the nominal value.

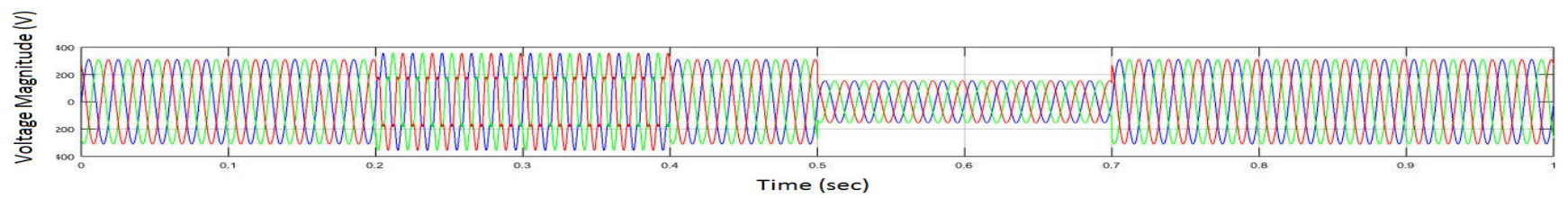

Fig. 11: Voltage Waveform showing Generated Sag and Swell at the Source Side

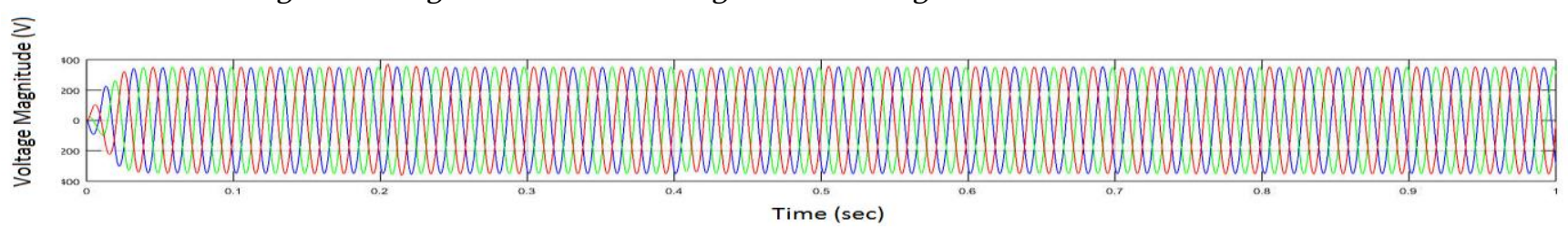

Fig. 12: Voltage Developed across the Sensitive Load with the Incorporation of DVR.

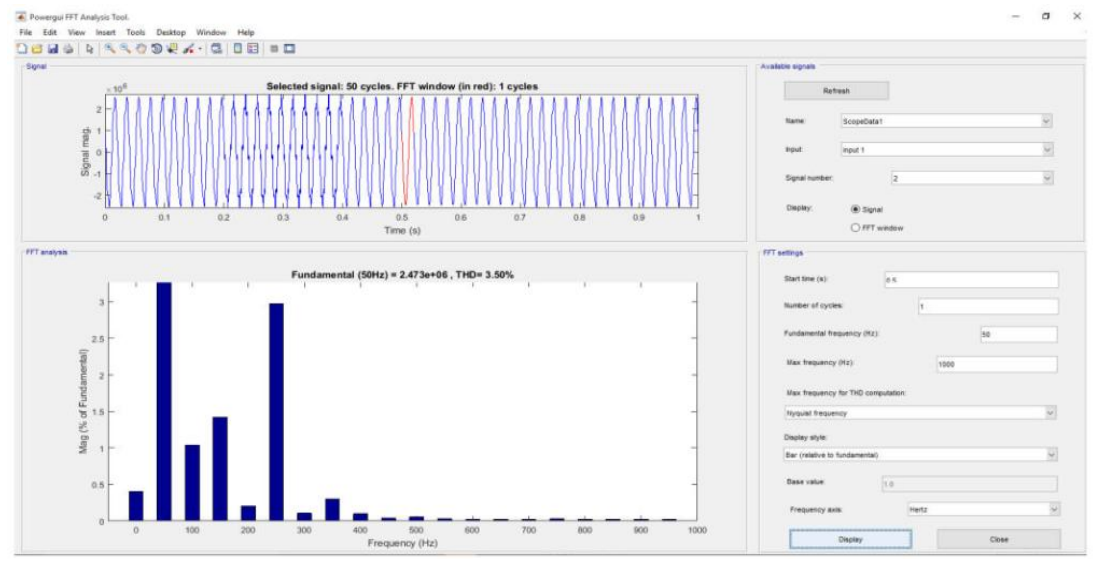

Fig. 13: THDV Developed on the Sensitive Load with Incorporation of DVR 


\section{REFERENCES}

[1] Nguyen, P. T. and Saha, T. K. "Dynamic Voltage Restorer against Balanced and Unbalanced Voltage Sags: Modeling and Simulation", IEEE Power Engineering Society General Meeting, Denver, CO, USA, June 6 - 10, pp. 1 - 6, 2004.

[2] Babaei, E. and Kangarlu, M. F. "A New Topology for Dynamic Voltage Restorers without DC Link", IEEE Symposium on Industrial Electronics and Applications (ISIEA 2009), Kuala Lumpur Malaysia, October 4 - 6, pp. 1016 - 1021, 2009.

[3] Boonchiam, P. and Mithulananthan, N. "Understanding of Dynamic Voltage Restorers through MATLAB Simulation", Thammasat Intl. Journal of Science and Technology, Vol. 11, Number 3, pp. 1-6, 2006.

[4] Benachaiba, C. and Ferdi, B. "Voltage Quality Improvement using DVR", Electrical Power Quality and Utilization Journal, Vol.16, Number 1, pp. 39-45, 2008.

[5] Jangid, R., Parkh, K. and Anjana P. "Reducing the Voltage Sag and Swell Problem in Distribution System using Dynamic Voltage Restorer with PI Controller", International Journal of Soft Computing and Engineering, Vol. 3, Number 6, pp. 193-202, 2014.

[6] Amrita, R. and Nadir, A. K. "Modeling \& Simulation of Dynamic Voltage Restorer (DVR) for Enhancing Voltage Sag", Sensors \& Transducers Journal, Vol. 87, Number 1, pp. 85-93, 2008.

[7] Kangarlu, M. F., Hosseini, S. H. and Sadigh, A. K. "Transformerless DVR Topology Based on Multilevel Inverter with Reduced Number of Switches", 1st Power Electronic \& Drive Systems \& Technologies Conference, IEEE, Tehran Iran, February 17 - 18, pp. 371 - 375, 2010.

[8] Almeida, A., Moreira, L. and Delgado, J. "Power Quality Problems and New Solutions", The Electrical and Computer Engineering Journal, Vol. 1, Number 1, pp. 1-9, 2003.

[9] Bhaskar, M. A., Dash, S. S., Subramani, C., Kumar, M. J., Giresh, P. R. and Kumar, M. V. "Voltage Quality Improvement using DVR", 2010 International Conference on Recent Trends in Information, Telecommunication and Computing, IEEE, Kochi Kerala India, March 12 -13, pp. 378 380, 2010.
[10] Devaraju, T., Veera- Reddy, V. C. and Kumar, M. V. "Role of Custom Power Devices in Power Quality Enhancement: A Review”, International Journal of Engineering Science and Technology, Vol.2, Number 8, pp. 3628-3634, 2010.

[11] Panda, B. and Behera, S. "Mitigation of Voltage Sag using DVR under Feedback and Feed Forward Control Scheme", International Journal of Engineering, Science and Technology, Vol. 2, Number 10, pp. 44 - 55, 2010.

[12] Rajasellaran, D. and Dash, S.S. "Mitigation of Voltage Sag and Voltage Swells by Dynamic Voltage Restorer", $3^{\text {rd }}$ International Conference on Advances in Recent Technologies in Communication and Computing (ARTCom 2011), Bangalore India, November 14 - 15, pp. 36 - 40, 2011.

[13] Ezinlarasan, S. and Balasurbramania, G. "Dynamic Voltage Restorer for Voltage Sag Mitigation using PI with Fuzzy Logic Controller", International Journal of Engineering Research and Applications, Vol. 3, Number 4, pp. 1090-1095, 2013.

[14] Taghikhani, M. A. "Phase Advanced Dynamic Voltage Restorer Control System Design", International Journal of Control Science and Engineering, Vol. 2, Number 4, pp. 60 - 68, 2012.

[15] Srisailam, C. H. and Sreenivas, A. "Mitigation of Voltage Sags/Swells by Dynamic Voltage Restorer using PI and Fuzzy Logic Controller", International Journal of Engineering Research and Applications, Vol. 2, Number 4, pp. 1733 - 1737, 2012.

\section{APPENDIX}

\begin{tabular}{ll} 
& DVR Parameters \\
\hline Component & Parameter \\
\hline Source & 3-phase, 415V, 50Hz \\
& $\begin{array}{l}\text { 3-phase full bridge PWM IGBT } \\
\text { based, 12 pulse, }\end{array}$ \\
Converter & Snubber resistance $=100 \mathrm{k} \Omega$ \\
& Internal resistance $=1 \mathrm{k} \Omega$ \\
RC Load & $\mathrm{R}=60 \Omega, \mathrm{C}=6.6 \mathrm{mF}$ \\
Injection & Vrms $=380 \mathrm{~V}, \mathrm{Rm}=0.02 \Omega, \mathrm{Lm}=$ \\
Transformer & $0.02 \mathrm{H}$ \\
Inverter Filter & $\mathrm{L}=1000 \mathrm{H}, \mathrm{C}=2000 \mu \mathrm{F}$ \\
DC link capacitor & $50^{6} \mathrm{~F}$ \\
\hline
\end{tabular}

